\title{
WWTEREFEEETECWOLÓGCA
}

\section{CULTIVO ORGÂNICO DA CANA DE AÇÚCAR}

\author{
ORGANIC CULTIVATION OF SUGARCANE
}

\author{
Ivan Freitas Possebon - ifp.possebon@outlook.com \\ Henrique Quero Polli - henrique.polli@fatectq.edu.br \\ Faculdade de Tecnologia de Taquaritinga (Fatec) - Taquaritinga - São Paulo - Brasil \\ DOI: $10.31510 /$ infa.v17i1.832
}

\begin{abstract}
RESUMO
O presente trabalho visa avaliar os diferenciais da produção de cana-de-açúcar de maneira orgânica, discorrendo sobre os motivadores, os impactos ambientais, econômicos e sociais e as vantagens e desvantagens da produção de cana seguindo o protocolo orgânico e comparando com dados da produção de modo convencional a fim de identificar as viabilidades técnicas e econômicas em se adotar este procedimento. Desta forma, realizou-se uma revisão literária, por meio de leitura de livros; artigos; jornais, os quais tratam a produção de cana orgânica como a opção mercadológica sustentável para uma sociedade moderna. Tecnicamente sistema de produção orgânico demonstra ser viável ambientalmente e economicamente, principalmente para pequenos produtores, porém, há a necessidade de se realizar mais estudos considerando diferentes regiões e tamanhos de propriedades, bem como o consorciamento com outras culturas agrícolas.
\end{abstract}

Palavras-chave: Cana de açúcar. Cultivo. Agricultura orgânica. Colheita. Açúcar e Álcool.

\begin{abstract}
The present work aims to evaluate the differentials of sugarcane production in an organic way, discussing the motivators, the environmental, economic and social impacts and the advantages and disadvantages of sugarcane production following the organic protocol and comparing it with production data conventionally in order to identify the technical and economic feasibility of adopting this procedure. In this way, a literary review was carried out, through the reading of books; articles; newspapers, which treat the production of organic cane as the sustainable marketing option for a modern society. Technically, the organic production system proves to be environmentally and economically viable, mainly for small producers, however, there is a need to carry out further studies considering different regions and sizes of properties, as well as intercropping with other agricultural crops.
\end{abstract}

Keywords: Sugarcane. Cultivation. Organic agriculture. Harvest. Sugar and alcohol. 


\section{INTRODUÇÃO}

A cana de açúcar (Saccharum Spp) é uma das culturas de maior importância social, econômica e ambiental, tendo atingido uma produção de 600 milhões de toneladas em 8,5 milhões de hectares no Brasil, país que é o maior produtor mundial da cultura (VEIGA Filho et al, 2008). É a partir dela que são feitos dois produtos essenciais para a economia: o açúcar e o álcool, o último utilizado tanto na fabricação de bebidas alcoólicas como em forma de combustível para os carros.

Hoje, o Brasil é o maior produtor mundial de cana, o primeiro também na produção e na exportação de açúcar e o segundo maior produtor e exportador de etanol, FREITAS VIAN, (2007). A cana de açúcar foi introduzida na China bem antes do início da Era Cristã. Na Europa foi introduzida através dos árabes, onde foi iniciado o seu cultivo. Com o descobrimento da América foi permitido à expansão das áreas de cultivo da cana de açúcar, em que as primeiras mudas, chegaram ao Brasil em 1502. Foi instalada no Brasil no período da época da colonização portuguesa, passando a ser a primeira atividade produtiva, e desde então a dimensão territorial, os impactos ambientais, sociais e econômicos decorrentes da atividade foram crescendo junto com a expansão do setor. Foi a partir de 1930, que teve início o planejamento da agroindústria canavieira nacional, por meio de um Estado centralizador e coordenador de grandes decisões nacionais, criando o Instituto do Álcool e do Açúcar (IAA). A partir de 1975 o Brasil se tornou o pioneiro na área de biocombustíveis devido a criação do Programa Nacional do Álcool (Proálcool), que foi criado para incentivar as Usinas a produzirem o etanol a partir da cana-de-açúcar. RODRIGUES, (2010).

Segundo dados da União da Indústria de cana-de-açúcar (2016), este setor do Agronegócio Brasileiro destaca-se como o maior produtor e exportador global de açúcar, sendo responsável por $20 \%$ da produção e $40 \%$ da exportação, e o segundo maior produtor global de etanol, representando $26 \%$ da produção. O PIB do setor é estimado em US 40 bilhões, correspondendo a $2 \%$ do PIB brasileiro. A cadeia de produção mostra-se ainda um importante gerador de empregos, sendo responsável pela geração de mais de 950 mil empregos formais diretos no setor produtivo e 70 mil produtores rurais de cana-de-açúcar independentes. 
O objetivo desse estudo é avaliar a viabilidade técnica e econômica do cultivo orgânico, efetuar levantamento do custo de produção e a viabilidade do sistema orgânico depois da cana colhida, ressaltando a lucratividade, VPL, TIR e PAYBACK, bem como os produtos utilizados para a correção do solo e estimulantes de crescimento, o custo da colheita e da implantação do projeto orgânico.

\subsection{Cana de Açúcar}

Sabe-se que através de inúmeras pesquisas o Brasil é o maior produtor de cana de açúcar, possuindo duas regiões produtoras, sendo elas nordeste e o centro-sul com safras alternadas, e mantendo sua presença no mercado mundial ao longo do ano todo. Em termos regionais, o Brasil apresenta períodos distintos da safra: de setembro a março no Norte-Nordeste, e de abril a novembro no Centro-Sul, MACHADO, (2008).

O país produz etanol durante o ano todo, as usinas têm produção em torno de 71 kg de açúcar e 42 litros de etanol para cada tonelada de cana processada. O etanol pode ser obtido através da cana-de-açúcar, milho, beterraba, mandioca, batata, etc. A matériaprima é submetida a uma fermentação alcóolica, com ação de micro-organismo Sacchromyces cerevisiae. Todavia a cana é a mais utilizada, por apresentar maior produtividade FRANCISCO, (2014).

De acordo com PACHECO (2011), o Brasil encontra-se em uma posição relevante no que se refere á produção de etanol, apresentando vantagens na tecnologia de produção, liderança na agricultura de energia e mercado de biocombustíveis sem ampliar a área destinada á produção de alimentos. A matriz energética brasileira já é considerada um belo exemplo de sustentabilidade, pois comparada a média mundial (14\% de fontes renováveis), o Brasil utiliza 46,8\% dessas fontes.

Merece destaque o estado de São Paulo, que produz próximo de $60 \%$ de toda a cana, açúcar e etanol do país. O segundo maior produtor é o estado do Paraná, com $8 \%$ da cana moída no Brasil. (CTC - 2005).

No meio dessa produção comum de cana de açúcar, há a produção orgânica de cana de açúcar, onde durante o seu plantio evita-se o uso de fertilizantes, e adubos químicos, evitando assim contaminação do solo. 
O objetivo desse estudo é avaliar a viabilidade técnica e econômica do cultivo de cana orgânica, frente ao cultivo convencional.

\subsection{Produção orgânica da cana de açúcar}

Para que o alimento comercializado possa ser denominado orgânico, ele deve portar o selo que garante que foi certificado através de auditoria sobre a produção. Para isso, deve respeitar todos os requisitos descritos na lei $\mathrm{n}^{\circ} 10.831$, de 2003. Considera-se sistema orgânico de produção agropecuária aquela em que se adotam técnicas específicas, com a otimização do uso dos recursos naturais e socioeconômicos disponíveis e o respeito à integridade cultural das comunidades rurais, com objetivo de sustentabilidade econômica e ecológica, maximização dos benefícios sociais e minimização da dependência de energia não renovável.

O termo orgânico refere-se a um sistema baseado em princípios ecológicos e não convencional de cultivo da terra. Segundo definição da International Federation of Organic Agriculture Movements (IFOAM, 2005), a agricultura orgânica é um sistema de produção que promove a saúde dos solos, ecossistemas e pessoas. Têm como base os processos ecológicos, biodiversidade e ciclos adaptados ás condições locais em alternativa ao uso de insumos com efeitos adversos.

Devido à conjuntura econômica, muitos têm passado a questionar o modelo agrícola que foca apenas na produtividade num prazo curto de tempo, com a utilização de agrotóxicos e fertilizantes. Agricultores e pesquisadores passam a considerar que a fertilidade do solo pode ir além do uso do calcário e NPK. Mais voltado para a proteção do solo contra a erosão, com rotação e diversificação de culturas, com preservação da matéria orgânica, da atividade biológica do solo e do equilíbrio nutricional das plantas, esta visão mais holística leva á redução da dependência do agricultor aos insumos externos (ALMEIDA, 1991, citado por BUSATO et al, 2009).

A agricultura orgânica começou a se estabelecer no Brasil a partir de 1976, buscando diminuir o impacto ambiental ocasionado pela atividade agrícola e industrial, e também produzir alimentos mais saudáveis e livres de produtos químicos, como os agrotóxicos, que nos últimos 30 anos tiveram seu uso expandido na agricultura convencional. CASEMIRO; TREVISAN, (2009). 
Atualmente, no Brasil, a Lei Federal 10.831/2003 regulamenta 3 sistemas de certificação de produtos orgânicos: i) a certificação auditada individual; ii) a certificação auditada em grupo; e iii) o sistema participativo de garantia (certificação participativa ou SPG), também chamada de certificação participativa em rede (CPR) BRASIL, (2003). O objetivo do cultivo orgânico é oferecer ao consumidor final vegetais de qualidades e que não tragam nenhum risco á saúde.

Em uma das pesquisas de identificação de nutrientes na cana-de-açúcar realizadas pela UFG Universidade Federal de Goiás foram encontrados os principais resultados, sendo do teor de potássio que está realmente elevado devido à aplicação de vinhaça que ainda é permitida nos canaviais orgânicos, apesar de ser mais conhecida no canavial comum, outro resultado foi o baixo teor de material orgânico, mesmo que o canavial não esteja sendo queimado.

O estado do Goiás ocupa as primeiras posições na produção de cana de açúcar orgânica no Brasil produz: cerca de 63,5\% da produção nacional em 2016/2017, de acordo com o Ministério da Agricultura, Pecuária e Abastecimento (MAPA). Segundo dados da União da Indústria de Cana-de-Açúcar (Unica), na safra 2016/2017 da Região Centro-Sul de açúcar orgânico, a produção foi de 181.438 toneladas, sendo que esse tipo de açúcar representa $0,51 \%$ da produção total do Centro-Sul. O Paraguai é os que mais produzem açúcar orgânico. O Brasil produz em torno de 181 mil toneladas e o Paraguai 96 mil toneladas.

\subsubsection{Procedimentos para a produção}

Os padrões de certificação de produção orgânica fornecem orientação sobre técnicas de produção, buscando potencializar a utilização dos recursos naturais e socioeconômicos disponíveis, priorizando o cuidado com o meio ambiente, manejando seus recursos de modo equilibrado, promovendo maior valorização do homem no campo, sua família e de seu trabalho. Dependendo da certificadora existem padrões a serem seguidos para a produção de cana orgânica. Em geral exigem:

Período inicial - O local onde será implantado o sistema orgânico deve ser preparado e ter alguns anos (pelo menos quatro) sem uso de pesticidas, produtos químicos e, principalmente, sem queimadas. Deve estar definido um plano de manejo da paisagem, de tal forma que o uso da terra promova a integração da atividade produtiva 
com a manutenção dos ecossistemas, prevendo a implantação de corredores florestais e/ou ilhas de diversidade na área cultivada.

Solo e o cultivo da cana - Deve ser feito com o mínimo de impacto na estruturação do solo, e devem ser adotadas práticas de conservação do solo e dos recursos hídricos. O manejo da cana deve prever a recuperação e a manutenção da fertilidade do solo. A atividade agrícola deve promover a conservação dos ecossistemas, a conservação da biodiversidade e sua recuperação.

Variedade de cana - Não pode ser transgênica.

Defensivos - Devem ser utilizados métodos de controle integrado, priorizando o controle biológico de pragas. Em casos extremos, algumas certificadoras aceitam a utilização de produtos menos agressivos, desde que haja um plano de uso de produtos e dosagens menos agressivas e uma total proteção ao trabalhador. O mato é controlado principalmente pela manutenção da palhada de cana do cultivo anterior. Capinas manuais são também necessárias, em áreas onde a infestação é alta. O controle do mato pode ser um dos gargalos do processo de produção da cana orgânica, uma vez que exige grande mão-de-obra e onera o processo. Existem tentativas de plantar misturas de adubos verdes na entrelinha da cana, porém ainda não é uma prática bem definida.

Fertilizantes e corretivos - Os fertilizantes permitidos são de origem orgânica ou minerais de baixa solubilidade, como os fosfatos naturais, calcário ou rochas moídas. A vinhaça e a torta de filtro são permitidas e fornecem praticamente todo o potássio e fósforo necessários, além de parte do nitrogênio. Os compostos também são utilizados, assim como os estercos animais. Deve-se realizar a rotação de culturas e adubação verde nas áreas de reforma do canavial com leguminosas, para fixação biológica do nitrogênio, e com gramíneas, para a melhoria da estrutura física do solo. Cobertura morta promovida pela manutenção da palhada de cana é altamente indicada.

Colheita - Apenas é permitida a colheita sem queima, mecanizada ou não. A colheita mecânica com cana queimada é terminantemente proibida. Na fase industrial, existem também algumas restrições. As indústrias devem ser autossustentáveis do ponto de vista energético. Devem promover o descarte adequado de todos os resíduos e observar toda a legislação existente para as emissões de poluentes no ambiente. Não poderá utilizar substâncias químicas durante o processamento do açúcar e do álcool. Sendo permitido apenas o uso de alguns floculantes durante o processo de clarificação. 
Produtos como cal ou calcário e polímeros naturais, como os obtidos a partir de acácia negra, são permitidos como agentes clarificantes.

\subsubsection{Impactos Ambientais}

A produção de qualquer cultura agrícola em larga escala pode trazer modificações aos aspectos físicos, químicos e biológicos do ambiente, refletindo em diversas formas de impactos ambientais. Com a cana-de-açúcar, sendo produzida nos meios convencionais, não é diferente.

\subsubsection{Agroquímicos}

Com a utilização de agroquímicos, há a questão da poluição do solo, da água, da vegetação nativa entornos dos canaviais e sua respectiva fauna é importante e deve ser considerado numa grande expansão. Os fatores que podem agravar o risco de contaminação ambiental é o uso excessivo e intenso de herbicidas no cultivo da cana para uniformizar a lavoura na colheita e a forma de aplicação utilizada. O uso de adubos solúveis são fontes difusas de contaminação do solo e de lençóis freáticos. Ponce, 2019, estudando os impactos ambientais potenciais em sistemas de produção orgânico e convencional de cana-de açúcar, utilizando a Avaliação do Ciclo de Vida (ACV), observou que, no caso das categorias Toxicidade humana e Ecotoxicidade terrestre, as emissões de metais resultantes da utilização dos fertilizantes sintéticos representaram uma parcela significativa dos resultados para áreas cultivadas como manejo convencional da cana quando comparados às áreas de cultivo orgânico. O Brasil é o quarto consumidor mundial de substâncias químicas tóxicas utilizadas na agricultura. (RAPHAEL MACHADO, 2008). A utilização da vinhaça, na fertirrigação, supre parte dos nutrientes para a cultura, porém podem ser fontes importantes de poluição, em contato com áreas frágeis de aquíferos, seja em lagoas, nos canais de transportes ou mesmo em locais de aplicação. (PASCHOAL, 1994).

\subsubsection{Queimadas}

Mesmo existindo no Estado de São Paulo uma lei que prevê a redução progressiva (25\% a cada cinco anos) na área de queimada de cana em favor da 
mecanização (GONÇALVES, 2002), esta prática degradatória ainda gera polêmica. Este é um dos pontos mais criticados e polêmicos do sistema produtivo sucroalcooleiro, seja pela morte de animais durante este processo ou por causar problemas sérios á saúde dos trabalhadores, que respiram a fuligem durante seu trabalho, como para a população das cidades onde atividade canavieira é conduzida, embora em muitas regiões onde a colheita da cana já é feita com mais de 70\% mecanizada, como a de Ribeirão Preto, para aumentar o rendimento das máquinas a cana continua sendo queimada. Vários trabalhos demonstram os riscos de morbidade e mortalidade em populações exposta a fumaça proveniente das queimadas (ARBEX et al 2004).

Miranda e Avellar, 2008, ao estudarem a qualidade da riqueza faunística de vertebrado terrestre existentes em áreas cultivadas com cana-de-açúcar orgânica e nos habitats adjacentes sob manejo agroecológico, concluíram que a manutenção das práticas orgânicas, sem utilização de agroquímicos ou fogo, associada a várias práticas agroambientais, é fundamental para a conservação da biodiversidade, que apresentou elevados índices comparados as áreas com plantio convencional.

\subsubsection{Produções em pequenas, médias e grandes escalas}

$\mathrm{Na}$ década de 80 esse sistema de plantio foi intensificando, pela Usina São Francisco de Sertãozinho, com um projeto denominado "cana verde". No ano de 1994, iniciou-se a produção orgânica da cana de açúcar em açúcar. (MIRANDA \& MIRANDA, 2004). Porém as primeiras lavouras foram certificadas no Brasil em 1997 no estado de São Paulo. O sistema de cultivo orgânico de cana-de-açúcar envolve a aplicação de técnicas alternativas de cultivo, com adubação orgânica, controle mecânico de plantas infestantes e uso de inseticidas naturais e controle biológico de pragas, sem adição de qualquer defensivo ou adubo químico e com colheitas sem queima (PASCHOAL, 1994).

Alguns estudos mostram que a migração do modelo convencional para o orgânico, pode trazer bons resultados ambientais para as propriedades agrícolas sem afetar a qualidade do produto final. MINGUETTI, (2012), estudando a influência dos sistemas de produção, convencional e orgânico, na qualidade da cana-de-açúcar (Saccharum spp) e do açúcar mascavo, concluiu não haver diferenças significativas entre os diferentes modelos de produção, no que diz respeito à qualidade de produto 
final, sugerindo que ambas as técnicas podem ser aplicadas a depender do objetivo de mercado destes agricultores.

\section{PROCEDIMENTOS METODOLÓGICOS}

Para o desenvolvimento deste artigo, realizou-se uma revisão literária, por meio de leitura de livros; artigos; jornais, os quais tratam a produção de cana orgânica como a opção mercadológica sustentável para uma sociedade moderna.

\section{VIABILIDADES ECONÔMICAS}

A avaliação da viabilidade econômica da cultura de cana-de-açúcar não é simples, pois, ao contrário de outras grandes culturas do país como soja e milho, a cultura da cana-de-açúcar pode ser explorada em um ciclo que pode ultrapassar os 6 anos como colheitas anuais. Desta forma, os gastos realizados para renovação do plantio ou mesmo para o plantio da cultura, devem ser contrastados com os resultados que vão além da primeira colheita.

De modo geral os custos para produção do orgânico são, em média, 15\% a 20\% mais caros do que o branco tradicional, em face da maior dificuldade operacional para sua fabricação e do manejo da lavoura. Ricardo Steckelberg, engenheiro e consultor de balanço de massa e energia em usinas de açúcar pelos Estados Unidos, explica que, para obtenção do açúcar orgânico, o diferencial de custos começa na lavoura, pois produtos químicos são proibidos para o cultivo da cana, sendo necessária a aplicação de adubos orgânicos. "O custo deste plantio vai depender da disponibilidade do adubo orgânico e do custo de logística para o transporte. Para o cultivo da cana orgânica é necessário eliminar o uso de fertilizantes, pesticidas e reguladores de crescimento produzidos sinteticamente por aproximadamente três anos, dependendo do mercado importador." SIAMIG (2018).

Os produtos orgânicos podem ser mais caros devido ao fato de que o produtor se preocupa com a preservação do meio ambiente e tem compromisso com a qualidade de vida de seus empregados. A oferta em relação à procura por produtos mais saudáveis 
também eleva o preço no mercado. Mas, tanto em supermercados como nas feiras livres, é possível adquirir produtos orgânicos com preços compatíveis. Escolher produtos orgânicos estimula o crescimento desta prática, aumenta a oferta e diminui seu preço ao consumidor. $\mathrm{O}$ açúcar orgânico tem um marketing muito forte como produto natural e pela preservação do meio ambiente. Alemanha, Japão e Estados Unidos são fortes compradores desse tipo de açúcar e isso gera uma oportunidade importante para agregar valor ao produto. Entretanto, ele também sofre influência do mercado internacional e seu preço pode variar entre 50 e 100\% acima do açúcar branco, dependendo da cor e da qualidade do açúcar produzido, conforme comenta Ricardo Steckelberg, SIAMIG (2018).

RAPASSI, (2008) avaliando questões técnicas e econômicas da produção da cana-de-açúcar (Saccharum spp) nos sistemas de cultivo convencional e orgânico na região oeste do Estado de São Paulo concluiu que a implantação da cultura o valor foi de $28,26 \%$ maior no sistema orgânico, quando comparado com o convencional e os custos de produção também foram maiores no sistema orgânico, chegando esta diferença a pouco mais de $8 \%$ no primeiro corte. Porém, ainda segundo a autora, considerando os preços pagos na região estudada, na análise de investimentos, considerando cinco cortes na cana-de-açúcar, os resultados foram satisfatórios, a taxa interna de retorno TIR para o sistema convencional foi de 14,19\% e no sistema orgânico o valor foi bem maior (24,09\%), apesar disso, produtores muitas vezes não se encontram motivados para migrarem para o sistema orgânico, devido, principalmente, as exigências das certificadoras, como por exemplo, tempo de espera que a área deve permanecer sem aplicar nenhum insumo agrícola; a burocracia para conseguir a certificação, dependência de vistorias do certificador, entre outros aspectos.

Ainda há uma escassez muito grande de estudos buscando avaliar modelos de produção de cana-de-açúcar orgânica, bem como, pouco incentivo sejam das grandes indústrias, seja das políticas governamentais para que o pequeno produtor, possa migrar para o modelo de produção orgânica, porém, observa-se no levantamento feito neste trabalho, que há uma tendência de aumento em razão da viabilidade econômica, técnica e ambiental em se adotar este modelo de produção. 


\section{CONCLUSÃO}

O modelo de produção estudado emprega a integração de técnicas agronômicas e ecológicas voltadas à produção orgânica e promoveu uma grande transformação no ambiente agrícola, respeitando as legislações vigentes e normas da produção orgânica, e diferem das práticas usuais empregadas no setor, caraterizadas pela degradação ambiental.

Os sistemas de produção de cana-de-açúcar ainda são bastante heterogêneos a nível nacional, no que pese a modernização tecnológica dessa atividade. O setor canavieiro emprega desde tecnologias de pontas até práticas que datam do neolítico, como o uso das queimadas para facilitar a colheita.

Conclui-se que o sistema de produção orgânico pode ser adotado para o cultivo de cana-de-açúcar.

A produção de cana-de-açúcar orgânica torna-se uma alternativa viável para a agricultura familiar, quando integrada em sistemas diversificados e sustentáveis. Dessa forma o agricultor familiar pode tanto aumentar a sua renda com a fabricação artesanal, organizado individualmente ou em formas de cooperação, dos subprodutos da cana-deaçúcar. Há a necessidade de se ampliar estudos buscando avaliar novos modelos de produção de cana-de-açúcar orgânica, bem como, aumentar incentivos de grandes indústrias, e de políticas governamentais para que o pequeno produtor possa migrar para o modelo de produção orgânica.

\section{REFERÊNCIAS}

ARBEX, Marcos Abdo et al. Queima de biomassa e efeitos sobre a saúde. $J$. bras. pneumol. [online]. 2004, vol.30, n.2,

BRASIL. Lei 10.831 de 23 de dezembro de 2003 que dispõe sobre a agricultura orgânica e dá outras providências. Diário Oficial da União, seção 1, p. 8, 24 dez. de 2003.

BRASIL. Ministério da Agricultura, Pecuária e Abastecimento. Balanço nacional da canade-açúcar e agroenergia. Brasília, DF, 2007. 140 p..

BUSATO, Jader Galba et al. Guia para adubação orgânica baseado na experiência com solos e resíduos no Norte Fluminense. Disponível em: http://www.microbacias.rj.gov.br/conteudo/compartilhados/pesquisa participativa_apoio tecnic 
o/14\%20-\%20Guia\%20para\%20aduba\%C3\%A30\%20org\%C3\%A2nica.pdf>. Acesso em: 17 fev. 2020.

CASEMIRO, A. D.; TREVISAN, S. D. P. Alimentos Orgânicos: Desafios para o Domínio Público de um conceito. In: International Workshop Advances In Cleaner Production. P 1-9, 2009.

FRANCISCO, Wagner Cerqueira. Etanol. Brasil Escola. Disponível em: https://brasilescola.uol.com.br/geografia/etanol.htm. Acesso em 23 de setembro de 2019.

GONÇALVES, Daniel Bertoli. A regulamentação das queimadas e as mudanças nos canaviais paulistas. 1. Ed. São Carlos-SP: Rima Editora, 2002. V. 1. 127 p.

IBGE - INSTITUTO BRASILEIRO DE GEOGRAFICA E ESTATÍSTICA. Nova Cana. CTC, 2005. Disponível em: https://www.novacana.com/cana/producao-cana-de-acucar-brasil-emundo. Acesso em 13 de abril de 2020.

INTERNATIONAL FEDERATION OF ORGANIC AGRICULTURE MOVEMENTS (IFOAM). Site corporativo. Disponível em: https://www.ifoam.bio/en/organiclandmarks/definition-organic-agriculture> Acesso em 18 mar. 2020.

MACHADO, Raphael. Sistemas de produção Orgânicos para a soca da cultura da cana-deaçúcar (SACCHARUM SPP), Consorciado com milho (ZEA MAYS), feijão (PHASEOLUS VULGARIS) E Mandioca (MANIHOT ESCULENTA), 2008, p.103.

MINGUETTI, Fausto Fabrício. Influencia dos sistemas de produção, convencional e orgânico, na qualidade da cana-de-açúcar (saccharum spp) e do açúcar mascavo. Dissertação (Mestrado) - Universidade Federal de São Carlos. 76 f. São Carlos: UFSCAR, 2012.

MIRANDA, José Roberto; AVELLAR, L. M. de Sistemas agrícolas sustentáveis e biodiversidade faunística: $\mathbf{O}$ caso da cana orgânica em manejo agroecológico. InterfacEHS Revista de gestão integrada em saúde do trabalho e meio ambiente, v. 3, n. 2, artigo 5. Abr./agosto, 2008.

MIRANDA, J. R.; MIRANDA, E. E. . Biodiversidade e Sistemas de Produção Orgânicos: Recomendações no Caso da Cana-de-Açúcar. Campinas: Embrapa Monitoramento por Satélite, 2004 (Documentos 27).

PACHECO, Thályta Fraga. Produção de Etanol: primeira ou segunda geração? Disponível em: https://core.ac.uk./download/pdf/15435555.pdf > Acesso em 08 mar. 2020.

PASCHOAL, Adilson D. Produção orgânica de alimentos: agricultura sustentável para os séculos XX e XXI. São Paulo: Globo, 1994. 191p.

PONCE, Rafaela Oliva. Avaliação do Ciclo de Vida dos sistemas de produção orgânico e convencional da cana-de-açúcar: um estudo comparativo. 201983 f. Dissertação (Mestrado 
em Administração) - Universidade Estadual Paulista - Júlio de Mesquita Filho. Jaboticabal, 2019.

RAPASSI, Rosalina Maria Alves. Avaliação técnica e econômica de sistemas de produção da cana-de-açúcar (Saccharum spp) convencional e orgânica na região oeste do Estado de São Paulo. 2008.p. 146 f. Tese (doutorado) - Universidade Estadual Paulista, Faculdade de Engenharia de Ilha Solteira, 2008.

RODRIGUES, Luciana Deotti. A cana-de-açúcar como matéria-prima para a produção de biocombustíveis: impactos ambientais e o zoneamento agroecológico como ferramenta para mitigação. 2010, p 54 .

ROSSETTO, Raffaella. O Sistema de Cultivo Orgânico. Impacto Ambiental. Visão Agrícola $\mathrm{n}^{\circ} 1$. Jan/Junho 2004, p.87.

SIAMIG. Associação das Indústrias Sucroenergéticas de Minas Gerais. História da cana-deaçúcar, 2018. Jornal da Bioenergia. Disponível em: http://www.siamig.com.br/institucional/cana-de-acucar

UNIÃO DA INDÚSTRIA DE CANA-DE-AÇÚCAR ÚNICA (2016).
$\begin{aligned} & \text { No } \\ & \text { <http://www.mme.gov.br/documents/36224/460139/UNICA- }\end{aligned}$

VEIGA FILHO, A. de A.; FRONZAGLIA, Thomaz.; TORQUATO, S.A. A necessidade de inovação tecnológica agrícola para sustentar o novo ciclo expansionista do setor sucroalcooleiro. In: DINARDO-MIRANDA, L. L.;.

VIAN, Carlos Eduardo de Freitas. (2007). Árvore do Conhecimento Cana-de-açúcar. Agência Embrapa de Informação Tecnológica- AGEITEC- 2007. Disponível em: < http://www.agencia.cnptia.embrapa.br/gestor/canaacucar/arvore/CONTAG01_62_22122006154 $\underline{840 . h t m l}$ 